\title{
TU/e EmonOWEN

\section{Electronic structure calculations and dynamics of CC coupling on nickel and cobalt}

Citation for published version (APA):

Burghgraef, H., Jansen, A. P. J., \& Santen, van, R. A. (1995). Electronic structure calculations and dynamics of CC coupling on nickel and cobalt. Journal of Chemical Physics, 103(15), 6562-6570.

https://doi.org/10.1063/1.470383

DOI:

10.1063/1.470383

Document status and date:

Published: 01/01/1995

Document Version:

Publisher's PDF, also known as Version of Record (includes final page, issue and volume numbers)

Please check the document version of this publication:

- A submitted manuscript is the version of the article upon submission and before peer-review. There can be important differences between the submitted version and the official published version of record. People interested in the research are advised to contact the author for the final version of the publication, or visit the $\mathrm{DOI}$ to the publisher's website.

- The final author version and the galley proof are versions of the publication after peer review.

- The final published version features the final layout of the paper including the volume, issue and page numbers.

Link to publication

\section{General rights}

Copyright and moral rights for the publications made accessible in the public portal are retained by the authors and/or other copyright owners and it is a condition of accessing publications that users recognise and abide by the legal requirements associated with these rights.

- Users may download and print one copy of any publication from the public portal for the purpose of private study or research.

- You may not further distribute the material or use it for any profit-making activity or commercial gain

- You may freely distribute the URL identifying the publication in the public portal.

If the publication is distributed under the terms of Article $25 \mathrm{fa}$ of the Dutch Copyright Act, indicated by the "Taverne" license above, please follow below link for the End User Agreement:

www.tue.nl/taverne

Take down policy

If you believe that this document breaches copyright please contact us at:

openaccess@tue.nl

providing details and we will investigate your claim. 


\title{
Electronic structure calculations and dynamics of CC coupling on nickel and cobalt
}

\author{
H. Burghgraef, A. P. J. Jansen, and R. A. van Santen \\ Laboratory for Inorganic Chemistry and Catalysis/Theory Group, Eindhoven University of Technology, \\ P.O. Box 513, $5600 \mathrm{MB}$ Eindhoven, The Netherlands
}

(Received 10 March 1995; accepted 13 July 1995)

\begin{abstract}
The carbon-carbon coupling of $\mathrm{C}$ (carbide) and $\mathrm{CH}$ (methylidyne), $\mathrm{C}$ and $\mathrm{CH}_{2}$ (methylene), and $\mathrm{C}$ and $\mathrm{CH}_{3}$ (methyl) on nickel has been studied with density functional theory using 7- and 13-atom cluster models. Formation of $\mathrm{CCH}_{3}$ (ethylidyne) turned out to be the most exothermic reaction on both clusters. Experimentally, $\mathrm{CCH}_{3}$ has been identified unambiguously with a structure perpendicular to the metal surface. Thus for the $\mathrm{C} / \mathrm{CH}_{3}$ coupling forming $\mathrm{CCH}_{3}$, we have determined the structure and potential energy surface in the coadsorbed state, transition state, and CC-formed state. The transition state is explicitly determined on the 7-atom cluster and the 13-atom cluster of both nickel and cobalt. We find transition state barriers of $57 \mathrm{~kJ} / \mathrm{mol}$ for the $\mathrm{Ni}_{7}$ cluster, $55 \mathrm{~kJ} / \mathrm{mol}$ for the $\mathrm{Co}_{7}$ cluster, $84 \mathrm{~kJ} / \mathrm{mol}$ for the $\mathrm{Ni}_{13}$ cluster, and $47 \mathrm{~kJ} / \mathrm{mol}$ for the $\mathrm{Co}_{13}$ cluster. The overall reaction energies are $-215,-184,-66$, and $-89 \mathrm{~kJ} / \mathrm{mol}$, respectively. Analysis of the TS shows a dominant contribution of the $\mathrm{CC}$ bond to the reaction coordinate. Cluster size effects play a role in all studied CC coupling reactions. (C) 1995 American Institute of Physics.
\end{abstract}

\section{INTRODUCTION}

A very interesting and important topic in heterogeneous catalysis is the conversion of $\mathrm{CH}_{4}$ to higher hydrocarbons. A well known method for $\mathrm{CH}_{4}$ activation is its steam reforming producing $\mathrm{CO}$ and $\mathrm{H}_{2}$ followed by the so-called FischerTropsch synthesis to various hydrocarbons. ${ }^{1}$ Whether $\mathrm{CH}_{4}$ or higher hydrocarbons are produced depends strongly on the transition metal surface and on reaction conditions, but on $\mathrm{Fe}, \mathrm{Co}$, and $\mathrm{Ru}$ a wide range of hydrocarbons is formed, whereas over $\mathrm{Ni}$ and $\mathrm{Pd} \mathrm{CH}_{4}$ is the principal product, while $\mathrm{Cu}$ shows no reaction at all. ${ }^{2}$ Kaminsky et al. ${ }^{3}$ have detected $\mathrm{CH}_{3}, \mathrm{CH}_{2}$, and $\mathrm{CH}$ as intermediates on $\mathrm{Ni}(111)$. An alternative, direct route is dissociation of $\mathrm{CH}_{4}$ to $\mathrm{CH}_{x}$ species over a silica supported transition metal catalyst at temperatures between 600-900 K, followed by carbon-carbon coupling and hydrogenation at temperatures around $370 \mathrm{~K} .{ }^{4}$ Again, the role of the metal is important: $\mathrm{Ru}$ and Co give a wide range of products as does Ni but in much lower yields, Pt yields only $\mathrm{C}_{1}$ and $\mathrm{C}_{2}$ products, while $\mathrm{Cu}$ and $\mathrm{Pd}$ show no carboncarbon coupling at all. Goodman and coworkers have identified $\mathrm{C}, \mathrm{CH}, \mathrm{CCH}_{2}$ (vinylidene), and $\mathrm{CCH}_{3}$ on $\mathrm{Ru}(0001)$ and $\mathrm{Ru}(11 \overline{2} 0)$ for this reaction using HREELS and TPD. ${ }^{5}$ Belgued et al. ${ }^{6}$ reported conversion of $\mathrm{CH}_{4}$ on a Pt-catalyst producing higher hydrocarbons upto $\mathrm{C}_{6}$ species.

Another important reaction in catalysis is $\mathrm{C}_{2} \mathrm{H}_{4}$ (ethylene) adsorption and its subsequent decomposition, which is well studied on $\mathrm{Pt}(111)$. Various mechanisms for $\mathrm{C}_{2} \mathrm{H}_{4}$ decomposition have been suggested, but almost all agree on $\mathrm{CCH}_{3}$ as the main product. Suggested intermediate structures are $\mathrm{CHCH}_{2}$ (vinyl) and $\mathrm{CCH}_{2},{ }^{7} \mathrm{CH}_{2} \mathrm{CH}_{3}$ (ethyl) and $\mathrm{CHCH}_{3}$ (ethylidene), ${ }^{8}$ or only $\mathrm{CHCH}_{3}{ }^{9}$ or $\mathrm{CHCH}_{2} \cdot{ }^{10}$ Somorjai et al. ${ }^{8}$ suggested a further decomposition of $\mathrm{CCH}_{3}$ to $\mathrm{CCH}_{2}$ and $\mathrm{CCH}$ (ethynyl). However, $\mathrm{CCH}_{3}$ remains the only species from $\mathrm{C}_{2} \mathrm{H}_{4}$ decomposition on $\mathrm{Pt}(111)$, which has been identified unambiguously by various methods. ${ }^{11}$ According to Fairbrother et al., ${ }^{12}$ studying the reactions of adsorbed $\mathrm{CH}_{3}$ on $\mathrm{Pt}(111), \mathrm{CH}_{3}$ reacts with $\mathrm{H}$ to form $\mathrm{CH}_{4}$ or dehydrogenates to $\mathrm{CH}_{2}$ and eventually $\mathrm{C}$ as shown by Zaera et al. ${ }^{13}$ These species can then form a $\mathrm{CC}$ bond. Again, $\mathrm{CCH}_{3}$ has been identified. According to them, $\mathrm{C}_{2} \mathrm{H}_{4}, \mathrm{CH}_{2} \mathrm{CH}_{3}, \mathrm{CHCH}_{3}$, and $\mathrm{CHCH}_{2}$ can all be ruled out, leaving $\mathrm{CCH}_{2}$ and $\mathrm{CCH}$ as the most likely other candidates. For the mechanism of $\mathrm{CCH}_{3}$ formation Fairbrother et al. ${ }^{12}$ suggest coupling of $\mathrm{C}$ and $\mathrm{CH}_{3}$.

Zheng et al. ${ }^{14}$ studied the carbon-carbon coupling reactions of $\mathrm{CH}_{3} / \mathrm{CH}_{3}, \mathrm{CH}_{3} / \mathrm{CH}_{2}$ and $\mathrm{CH}_{2} / \mathrm{CH}_{2}$ on $\mathrm{Cr}(110)$, $\mathrm{Ti}(0001)$, and $\mathrm{Co}(0001)$ using tight binding extended Hückel calculations and found a barrier for coupling $\mathrm{CH}_{3} / \mathrm{CH}_{3}$ and $\mathrm{CH}_{3} / \mathrm{CH}_{2}$ and an overall endothermicity. In contrast, the coupling between $\mathrm{CH}_{2} / \mathrm{CH}_{2}$ proceeded without a barrier and turned out to be exothermic. De Koster et al. ${ }^{15}$ using atom superposition electron delocalization molecular orbital (ASED-MO) theory found on $\mathrm{Rh}(111)$ high barriers for coupling $\mathrm{CH}_{3} / \mathrm{CH}_{2}$, which they attributed to strong steric repulsion between the hydrogen atoms. Koerts et al., ${ }^{16}$ also using ASED-MO theory searched for a low coupling barrier between $\mathrm{C} / \mathrm{C}, \mathrm{C} / \mathrm{CH}, \mathrm{C} / \mathrm{CH}_{2}$, and $\mathrm{C} / \mathrm{CH}_{3}$ on $\mathrm{Rh}(111)$. Except for $\mathrm{C} / \mathrm{CH}_{2}$, where a barrier of $95 \mathrm{~kJ} / \mathrm{mol}$ was calculated, they found rather high barriers, but slightly exothermic overall reactions. The barrier height again correlated with the number of $\mathrm{CH}$ bonds, i.e., the highest barrier was found for $\mathrm{C} / \mathrm{CH}_{3}$ coupling followed by $\mathrm{C} / \mathrm{CH}$ and $\mathrm{C} / \mathrm{C}$ coupling. Kang et $\mathrm{al}^{7}{ }^{7}$ studied theoretically ethylene and acetylene chemisorption on $\mathrm{Pt}(111)$ using again ASED-MO theory. They determined transition states and could thus compute activation barriers for their suggested intermediates. For $\mathrm{CCH}_{3}$ they predicted a structure perpendicular to the surface, which is also found experimentally, ${ }^{17}$ for $\mathrm{CCH}_{2}$ a bent structure, and the energetics of perpendicular and bent $\mathrm{CCH}$ turned out to be almost the same with a slight preference for the perpendicular structure. However, they computed a small barrier for $\mathrm{CCH}$ decomposition to form $\mathrm{C}$ and $\mathrm{CH}$. Furthermore, for the rearrangement of $\mathrm{CCH}_{2}$ to $\mathrm{CCH}_{3}$ they computed a barrier of 
$203 \mathrm{~kJ} / \mathrm{mol}$ and an endothermicity of $77 \mathrm{~kJ} / \mathrm{mol}$, which suggests no formation of $\mathrm{CCH}_{3}$ at all, contrary to experiment. Instead, they suggested formation of $\mathrm{CCH}$, which according to them is exothermic by $13 \mathrm{~kJ} / \mathrm{mol}$. Carter and Koel ${ }^{18}$ estimated surface reaction energies on $\mathrm{Pt}(111)$ and used these data to eliminate possible reaction pathways. According to them $\mathrm{C}_{2} \mathrm{H}_{4}$ adsorbs, isomerizes to $\mathrm{CH}_{3} \mathrm{CH}$, dehydrogenates to $\mathrm{CCH}_{3}$, which isomerizes to $\mathrm{CH}_{2} \mathrm{CH}$, which dehydrogenates further to $\mathrm{CHCH}, \mathrm{CCH}$, and finally $\mathrm{CC}$. One of their conclusions is the absence of $\mathrm{C}$ and $\mathrm{CCH}_{2}$. They predict that $\mathrm{CH}_{2}$ is the most stable $\mathrm{C}_{1}$ species and ethylidene $\left(\mathrm{CHCH}_{3}\right)$ the most stable $\mathrm{C}_{2}$ species. Shustorovich et al. ${ }^{19}$ used a bond order conservation (BOC) model to study among others the decomposition of $\mathrm{C}_{2} \mathrm{H}_{4}$ on $\mathrm{Pt}(111)$. According to them, this species is dehydrogenated to $\mathrm{CHCH}_{2}$, followed by dehydrogenation to $\mathrm{CCH}_{2}$, which is then predicted to isomerize to adsorbed $\mathrm{CHCH}$ (acetylene), which then desorbs. In their model $\mathrm{CCH}_{3}$ is not likely to form starting from $\mathrm{C}_{2} \mathrm{H}_{4}$.

In addition to the abundant data on $\mathrm{C}_{2} \mathrm{H}_{2}$ and $\mathrm{C}_{2} \mathrm{H}_{4}$ chemisorption on $\mathrm{Pt}(111)$, we have also found some $\mathrm{C}_{2} \mathrm{H}_{2} / \mathrm{C}_{2} \mathrm{H}_{4}$ chemisorption experiments on $\mathrm{Ni}$ and $\mathrm{Co}$ surfaces. According to Lehwald et al. ${ }^{20}$ and Demuth, ${ }^{21} \mathrm{C}_{2} \mathrm{H}_{4}$ directly decomposes to chemisorbed $\mathrm{C}_{2} \mathrm{H}_{2}$ on $\mathrm{Ni}(111)$, while $\mathrm{CCH}$ is formed on $\mathrm{Ni}(110)$, according to Stroscio et al. ${ }^{22}$ Zaera et al. ${ }^{23}$ studied $\mathrm{C}_{2} \mathrm{H}_{4}$ decomposition on $\mathrm{Ni}(100)$ and found evidence for $\mathrm{CHCH}_{2}$ formation. By raising the crystal temperature, they found evidence for subsequently $\mathrm{CHCH}$, $\mathrm{CCH}$, and $\mathrm{C}$. Zhu et al. ${ }^{24}$ showed the existence of $\mathrm{CCH}_{3}$ on $\mathrm{Ni}(111)$ at high coverages of $\mathrm{CHCH}$ and $\mathrm{CH}_{2} \mathrm{CH}_{2}$. Albert et al. ${ }^{25}$ chemisorbed $\mathrm{CHCH}$ and $\mathrm{CH}_{2} \mathrm{CH}_{2}$ on $\mathrm{Co}(0001)$, but found no further reaction of adsorbed $\mathrm{CHCH}$. However, adsorbed $\mathrm{CH}_{2} \mathrm{CH}_{2}$ decomposed according to them by a simultaneous scission of all $\mathrm{CH}$ bonds followed by $\mathrm{CC}$ bond scission. Finally, Lapinski et al. ${ }^{26}$ presented ir evidence for $\mathrm{CCH}_{3}$ formation on a alumina supported nickel catalyst starting from $\mathrm{CH}_{2} \mathrm{CH}_{2}$, while Anderson et al. ${ }^{27}$ reported the same for a silica supported cobalt catalyst.

We can conclude that in both direct $\mathrm{CH}_{4}$ dissociation and $\mathrm{C}_{2} \mathrm{H}_{4}$ decomposition $\mathrm{CCH}_{3}$ plays an important role. In addition, almost every possible $\mathrm{C}_{2} \mathrm{H}_{x}$ species is proposed as an intermediate by theoreticians as well as experimentalists. We think that it is interesting to investigate the reaction between a fully dehydrogenated $\mathrm{C}$ species and $\mathrm{CH}_{3}$ species, thereby avoiding the steric repulsion between hydrogen atoms, which results in a very high activation barrier as shown by others. Furthermore, the product $\mathrm{CCH}_{3}$ has been detected by various methods and on various substrates, as discussed above. Therefore, we have calculated the potential energy surface at the coadsorbed state (CS), the transition state (TS), and the CC-formed state $\left(\mathrm{CC}^{f} \mathrm{~S}\right)$ of $\mathrm{C} / \mathrm{CH}_{3}$ using an ab initio density functional approach, and treated the kinetics of the system by employing transition state theory. Specifically, we have taken a one layer 7-atom cluster, and a 13-atom spherical cluster of $\mathrm{Ni}$ and Co to model the substrate, in addition to our work on $\mathrm{CH}$ bond activation on these metals. ${ }^{28}$ Thus we have studied the following reactions:

$$
\mathrm{CH}_{3 a}+\mathrm{C}_{a} \stackrel{k_{\mathrm{CC}}^{f}}{\longrightarrow} \mathrm{CCH}_{3 a}
$$

and

$$
\mathrm{CCH}_{3 a} \stackrel{k_{\mathrm{CC}}^{c}}{\longrightarrow} \mathrm{CH}_{3 a}+\mathrm{C}_{a} \text {. }
$$

In Sec. II we give computational details, in Sec. III we discuss the electronic structure calculations, in Sec. IV the kinetic treatment, and in Sec. V we draw some conclusions.

\section{METHODS}

We have performed quasirelativistic calculations based on density functional theory (DFT) using the Amsterdam Density Functional program package (ADF) developed by Baerends et $a l^{29}$ The exchange-correlation potential used is based on quantum Monte Carlo simulations of Ceperley and Alder $^{30}$ of a homogeneous electron gas which has been parametrized by Vosko, Wilk, and Nusair. ${ }^{31}$ To correct for the overbinding inherent to the local density approximation (LDA), ${ }^{32}$ we have used a gradient corrected exchange energy functional ${ }^{33}$ in combination with the Stoll correction ${ }^{34}$ for correlation. For carbon a frozen core potential is used for the $1 s$ electrons; for nickel and cobalt the electrons up to $3 p$ are frozen. Relativistic effects were taken into account by first order perturbation theory. ${ }^{35}$ The basis sets are of double $\zeta$ quality, with the exception of the nickel and cobalt $d$ orbitals, which are triple $\zeta$ 's. On all atoms polarization functions are

(a)
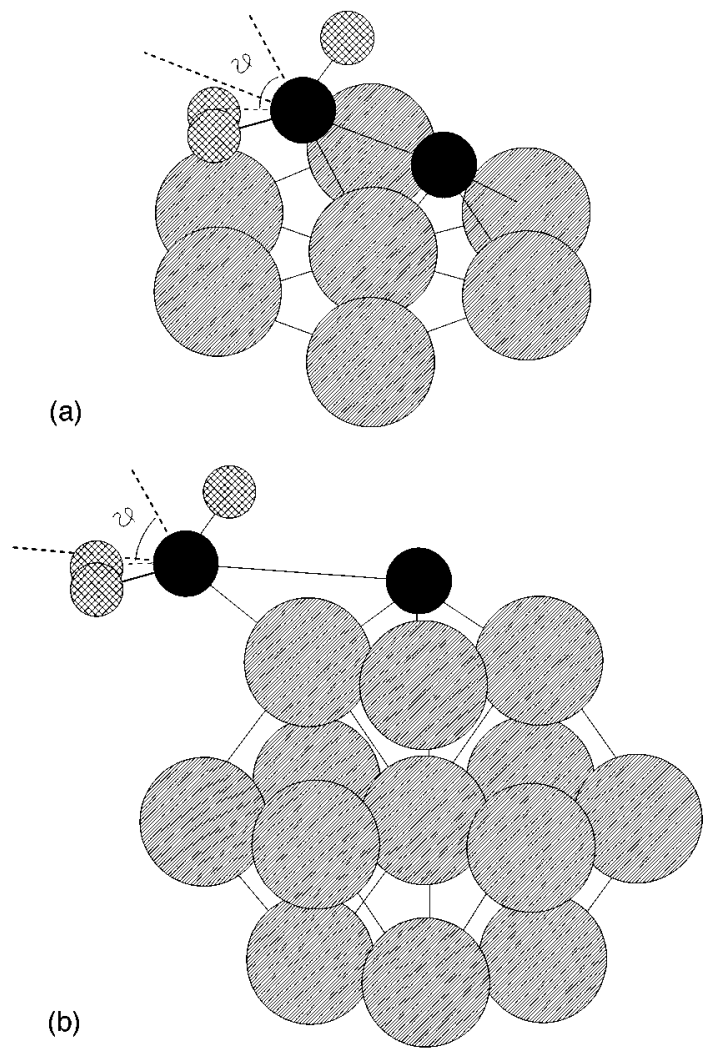

FIG. 1. Definition of optimized parameters on a one layer 7-atom cluster (a), and a spherical 13-atom cluster (b). Hydrogen atoms are denoted by diagonally cross-hatched small circles, carbon by a filled black medium circle, and metal atoms by large circles with diagonal lines. The dotted lines denote the $C_{3 v}$ axes of the $\mathrm{CH}_{3}$ group with respect to the $\mathrm{CC}$ bond. The $\mathrm{MC}_{1}$ bond (C), the $\mathrm{MC}_{2}$ bond $\left(\mathrm{CH}_{3}\right)$, the $\mathrm{CC}$ bond, and the tilt angle $\theta$ were optimized. For both clusters the bond distance of the bulk was used. 
included. As models for the substrate, we have used a one layer 7-atom cluster and a spherical 13-atom cluster [Figs. $1(\mathrm{a})$ and 1(b)], which have been discussed extensively before. ${ }^{36}$ For nickel clusters the bond distance was fixed at the bulk value of $2.49 \AA$, for cobalt clusters at the bulk value of $2.50 \AA$ A . Adsorption energies are calculated using Ziegler's transition state method ${ }^{37}$ and are given relative to the gas phase fragments with the same geometry. The CS was calculated by coadsorbing the two fragments at separated threefold sites at optimal adsorbate-substrate distances determined in previous studies. ${ }^{36}$ On the 13-atom cluster these sites are at the top and the bottom of the cluster. The additional degrees of freedom of the $\mathrm{CH}_{x}$ fragments were not allowed to relax, i.e., for all $\mathrm{CH}_{x}$ species we kept the $\mathrm{CH}$ distances at $1.08 \AA$, the $\mathrm{HCH}$ angles at $109.48^{\circ}$, the substrate- $\mathrm{CH}$ angles of $\mathrm{CH}_{3}$ at $109.48^{\circ}$, the substrate- $\mathrm{CH}$ angles of $\mathrm{CH}_{2}$ at $125.26^{\circ}$ and the substrate- $\mathrm{CH}$ angles of $\mathrm{CH}$ at $180^{\circ}$.

The TS of $\mathrm{CCH}_{3}$ was explicitly calculated by a four dimensional grid in the $\mathrm{MC}_{1}, \mathrm{MC}_{2}$, and $\mathrm{CC}$ distances and the $\mathrm{CH}_{3}$ tilt angle with respect to the activated $\mathrm{CC}$ bond $(\theta)$ [Figs. 1(a) and 1(b)]. The grid point energies were fitted to a second-order polynomial in the $\mathrm{MC}_{1}, \mathrm{MC}_{2}$, and $\mathrm{CC}$ distances and $\theta$. The $\mathrm{CC}^{f} \mathrm{~S}$ was determined by optimizing the $\mathrm{MC}_{1}$ and $\mathrm{CC}$ distances, keeping the product $\mathrm{CCH}_{x}$ at a threefold site, and keeping substrate-CC angles all at $180^{\circ}$ (perpendicular positions). Vibrational calculations were performed using the conventional GF method, ${ }^{38}$ where $\mathrm{G}$ is the kinetic energy matrix and $\mathrm{F}$ the force constant matrix. Kinetic properties were calculated according to transition state theory. ${ }^{39}$

\section{ELECTRONIC STRUCTURE CALCULATIONS}

Optimal parameters and energies of the $\mathrm{CS}$ and the $\mathrm{CC}^{f} \mathrm{~S}$ of $\mathrm{C} / \mathrm{CH}$ and $\mathrm{C} / \mathrm{CH}_{2}$ on $\mathrm{Ni}_{7}$ and $\mathrm{Ni}_{13}$, together with the CS, the TS and the $\mathrm{CC}^{f} \mathrm{~S}$ of $\mathrm{C} / \mathrm{CH}_{3}$ on $\mathrm{Ni}_{7}, \mathrm{Ni}_{13}, \mathrm{Co}_{7}$, and $\mathrm{Co}_{13}$ are shown in Table I. We conclude that formation of $\mathrm{CCH}$ $\left(\mathrm{CC}^{f} \mathrm{~S}\right)$ is endothermic on both clusters by $61-62 \mathrm{~kJ} / \mathrm{mol}$. Formation of $\mathrm{CCH}_{2}\left(\mathrm{CC}^{f} \mathrm{~S}\right)$ and $\mathrm{CCH}_{3}\left(\mathrm{CC}^{f} \mathrm{~S}\right)$ is strongly exothermic on $\mathrm{Ni}_{7}$, but the exothermicity is reduced on $\mathrm{Ni}_{13}$. For the $\mathrm{Ni}_{13}$ clusters we also optimized the adsorption energy of $\mathrm{CCH}_{x}\left(\mathrm{CC}^{f} \mathrm{~S}\right)$ as a function of the $\mathrm{MC}_{1}$ and $\mathrm{CC}$ distances for optimal $\mathrm{CH}$ distances of $\mathrm{CCH}_{x}$ in the gas phase. Although the effect on the $\mathrm{CH}$ distance was pronounced (optimal $\mathrm{CH}$ distances of $1.09,1.11$, and $1.13 \AA$ for $\mathrm{CCH}, \mathrm{CCH}_{2}$, and $\mathrm{CCH}_{3}$, respectively), the effect on the adsorption energies was maximal $3 \mathrm{~kJ} / \mathrm{mol}$. For the most exothermic reaction, the formation of $\mathrm{CCH}_{3}$, we determined the TS on $\mathrm{Ni}_{7}$, $\mathrm{Ni}_{13}, \mathrm{Co}_{7}$, and $\mathrm{Co}_{13}$. We find transition state barriers of 57 $\mathrm{kJ} / \mathrm{mol}$ on $\mathrm{Ni}_{7}, 84 \mathrm{~kJ} / \mathrm{mol}$ on $\mathrm{Ni}_{13}, 55 \mathrm{~kJ} / \mathrm{mol}$ on $\mathrm{Co}_{7}$, and 47 $\mathrm{kJ} / \mathrm{mol}$ on $\mathrm{Co}_{13}$. The geometry of the TS differs significantly between the 7- and 13-atom clusters of the same metal, but are quite similar for the 7-atom clusters as well as for the 13-atom clusters. Analysis of the TS shows a dominant contribution of the CC distance to the imaginary frequency, which characterizes the reaction coordinate. Therefore, we expect a correlation between $\mathrm{CC}$ bond distance and barrier height. Indeed, the TS of $\mathrm{Ni}_{7} / \mathrm{CCH}_{3}$ with a $\mathrm{CC}$ bond of 2.39 $\AA$ gives a slightly higher barrier $(57 \mathrm{~kJ} / \mathrm{mol})$ than the TS of $\mathrm{Co}_{7} / \mathrm{CCH}_{3}$ with a $\mathrm{CC}$ bond of $2.33 \AA$ and a barrier height of
TABLE I. Geometries $(\AA)$ and energies $(\mathrm{kJ} / \mathrm{mol})$ of the coadsorbed state (CS), the transition state (TS) and the CC-formed state $\left(\mathrm{CC}^{f} \mathrm{~S}\right)$ for the 7 - and 13-atom cluster models.

\begin{tabular}{|c|c|c|c|c|c|}
\hline System & $R_{\mathrm{MC}_{1}}$ & $R_{\mathrm{MC}_{2}}$ & $R_{\mathrm{CC}}$ & $\theta$ & E \\
\hline $\mathrm{Ni}_{7} / \mathrm{C} / \mathrm{CH}(\mathrm{CS})$ & 1.84 & 1.84 & 2.88 & $0.0^{\circ}$ & 0 \\
\hline $\mathrm{Ni}_{7} / \mathrm{CCH}\left(\mathrm{CC}^{f} \mathrm{~S}\right)$ & 1.98 & 3.03 & 1.31 & $0.0^{\circ}$ & 62 \\
\hline $\mathrm{Ni}_{7} / \mathrm{C} / \mathrm{CH}_{2}(\mathrm{CS})$ & 1.84 & 2.04 & 2.89 & $0.0^{\circ}$ & 0 \\
\hline $\mathrm{Ni}_{7} / \mathrm{CCH}_{2}\left(\mathrm{CC}^{f} \mathrm{~S}\right)$ & 1.90 & 3.02 & 1.41 & $0.0^{\circ}$ & -152 \\
\hline $\mathrm{Ni}_{7} / \mathrm{C}_{/} \mathrm{CH}_{3}(\mathrm{CS})$ & 1.84 & 2.43 & 2.99 & $0.0^{\circ}$ & 0 \\
\hline $\mathrm{Ni}_{7} / \mathrm{CCH}_{3}(\mathrm{TS})$ & 1.81 & 2.32 & 2.39 & $43.3^{\circ}$ & 57 \\
\hline $\mathrm{Ni}_{7} / \mathrm{CCH}_{3}\left(\mathrm{CC}^{f} \mathrm{~S}\right)$ & 1.85 & 3.09 & 1.57 & $0.0^{\circ}$ & -215 \\
\hline $\mathrm{Ni}_{13} / \mathrm{C} / \mathrm{CH}(\mathrm{CS})$ & 1.80 & 1.91 & 6.40 & $0.0^{\circ}$ & 0 \\
\hline $\mathrm{Ni}_{13} / \mathrm{CCH}\left(\mathrm{CC}^{f} \mathrm{~S}\right)$ & 2.03 & 3.09 & 1.31 & $0.0^{\circ}$ & 61 \\
\hline $\mathrm{Ni}_{13} / \mathrm{C} / \mathrm{CH}_{2}(\mathrm{CS})$ & 1.80 & 2.04 & 6.60 & $0.0^{\circ}$ & 0 \\
\hline $\mathrm{Ni}_{13} / \mathrm{CCH}_{2}\left(\mathrm{CC}^{f} \mathrm{~S}\right)$ & 1.95 & 3.07 & 1.41 & $0.0^{\circ}$ & -14 \\
\hline $\mathrm{Ni}_{13} / \mathrm{C} / \mathrm{CH}_{3}(\mathrm{CS})$ & 1.80 & 2.39 & 7.05 & $0.0^{\circ}$ & 0 \\
\hline $\mathrm{Ni}_{13} / \mathrm{CCH}_{3}(\mathrm{TS})$ & 1.82 & 2.16 & 2.15 & $25.9^{\circ}$ & 84 \\
\hline $\mathrm{Ni}_{13} / \mathrm{CCH}_{3}\left(\mathrm{CC}^{f} \mathrm{~S}\right)$ & 1.91 & 3.17 & 1.56 & $0.0^{\circ}$ & -66 \\
\hline $\mathrm{Co}_{7} / \mathrm{C} / \mathrm{CH}_{3}(\mathrm{CS})$ & 1.77 & 2.45 & 3.04 & $0.0^{\circ}$ & 0 \\
\hline $\mathrm{Co}_{7} / \mathrm{CCH}_{3}(\mathrm{TS})$ & 1.79 & 2.30 & 2.33 & $43.3^{\circ}$ & 55 \\
\hline $\mathrm{Co}_{7} / \mathrm{CCH}_{3}\left(\mathrm{CC}^{f} \mathrm{~S}\right)$ & 1.88 & 3.14 & 1.58 & $0.0^{\circ}$ & -184 \\
\hline $\mathrm{Co}_{13} / \mathrm{C} / \mathrm{CH}_{3}(\mathrm{CS})$ & 1.81 & 2.41 & 7.10 & $0.0^{\circ}$ & 0 \\
\hline $\mathrm{Co}_{13} / \mathrm{CCH}_{3}(\mathrm{TS})$ & 1.83 & 2.15 & 2.09 & $23.8^{\circ}$ & 47 \\
\hline $\mathrm{Co}_{13} / \mathrm{CCH}_{3}\left(\mathrm{CC}^{f} \mathrm{~S}\right)$ & 1.96 & 3.21 & 1.55 & $0.0^{\circ}$ & -89 \\
\hline
\end{tabular}

$55 \mathrm{~kJ} / \mathrm{mol}$. The effect is more pronounced on the 13-atom clusters: The TS of $\mathrm{Ni}_{13} / \mathrm{CCH}_{3}$ has a $\mathrm{CC}$ bond distance of $2.15 \AA$ and a barrier height of $84 \mathrm{~kJ} / \mathrm{mol}$, whereas the TS of $\mathrm{Co}_{13} / \mathrm{CCH}_{3}$ has a $\mathrm{CC}$ bond distance of $2.09 \AA$ and a barrier height of only $47 \mathrm{~kJ} / \mathrm{mol}$. Although in both cases the difference in CC bond length is $0.06 \AA$, the effect on barrier height is very different. We attribute this to the more compact TS at the 13-atom clusters. Except for the $\mathrm{MC}_{1}$ distance, the $\mathrm{MC}_{2}$ and $\mathrm{CC}$ distances and the tilt angle are significantly smaller on the 13-atom clusters, which results in a larger effect on the transition state barrier height, when the $\mathrm{CC}$ bond length changes. The same conclusion can be drawn starting from the $\mathrm{CC}^{f} \mathrm{~S}$ state. For $\mathrm{Ni}_{7} / \mathrm{CCH}_{3}$ the $\mathrm{CC}$ bond changes from 1.57 to $2.39 \AA$, an increase of $0.82 \AA$ in going from the $\mathrm{CC}^{f} \mathrm{~S}$ to the TS. The barrier height for this CC cleavage reaction is $272 \mathrm{~kJ} / \mathrm{mol}$. For $\mathrm{Co}_{7} / \mathrm{CCH}_{3}$ the $\mathrm{CC}$ bond changes from 1.58 to $2.33 \AA$, an increase of $0.75 \AA$ with a corresponding barrier height of $239 \mathrm{~kJ} / \mathrm{mol}$. For $\mathrm{Ni}_{13} / \mathrm{CCH}_{3}$ and $\mathrm{Co}_{13} / \mathrm{CCH}_{3}$ the changes in CC bond length are respectively 0.59 and $0.54 \AA$ with corresponding barrier heights of 150 and $136 \mathrm{~kJ} / \mathrm{mol}$.

Comparison of our CS results with the infinitely separated state (ISS) of adsorbed $\mathrm{C} / \mathrm{CH}_{x}$ showed up the existence of cluster size effects. This can be seen from Table II, which shows the charge on $\mathrm{C}, \mathrm{C}$ of $\mathrm{CH}_{x}, \mathrm{H}$ of $\mathrm{CH}_{x}$, the $\mathrm{CH}_{x}$ fragment, and on the cluster for all studied systems, together with the difference in energy between the adsorbed $\mathrm{C} / \mathrm{CH}_{x}$ in the ISS and the CS. The large positive energy difference indicates that adsorption in the CS is far more favorable than in the ISS. The magnitude and sign of this energy difference clearly prohibits interpretation in terms of a barrier to move along the surface. We discuss first the results for $\mathrm{C} / \mathrm{CH}$. The $\mathrm{CC}^{f} \mathrm{~S}$ shows a positive charge on $\mathrm{C}\left(0.33 e\right.$ on $\mathrm{Ni}_{7}, 0.55 e$ on $\mathrm{Ni}_{13}$ ). Also, the total charge on the cluster is by more than two electrons positive on the CS at $\mathrm{Ni}_{7}(2.06 e$ ), and by almost two electrons on $\mathrm{Ni}_{13}(1.99 e)$. The $\mathrm{CH}$ fragment is 
TABLE II. Charge (in electrons) on $\mathrm{C}\left(q_{\mathrm{C} 1}\right)$, on $\mathrm{C}$ of $\mathrm{CH}_{3}\left(q_{\mathrm{C} 2}\right)$, on $\mathrm{H}$ of $\mathrm{CH}_{x}\left(\Sigma_{q \mathrm{H}}\right)$, on $\mathrm{CH}_{x}\left(q_{\mathrm{CH}_{x}}\right)$, and on $M_{x}\left(\Sigma q_{\mathrm{M} x}\right)$ based on a Mulliken population analysis for the infinitely separated state (ISS) of adsorbed $\mathrm{C}^{-\mathrm{CH}_{x}}$, the coadsorbed state (CS), the transition state (TS) and the CC-formed state $\left(\mathrm{CC}^{f} \mathrm{~S}\right)$, together with the energy difference $(\mathrm{kJ} / \mathrm{mol})$ between the ISS and the CS for the 7- and 13-atom cluster models.

\begin{tabular}{|c|c|c|c|c|c|c|}
\hline System & $q_{\mathrm{C}_{1}}$ & $q_{\mathrm{C}_{2}}$ & $\Sigma_{q_{\mathrm{H}}}$ & $q_{\mathrm{CH}_{x}}$ & $\Sigma_{q \mathrm{M}_{x}}$ & $E_{\mathrm{ISS}}-E_{\mathrm{CS}}$ \\
\hline $\mathrm{Ni}_{7} / \mathrm{C} / \mathrm{CH}$ (ISS) & -0.39 & -0.39 & 0.13 & -0.26 & 0.65 & \\
\hline $\mathrm{Ni}_{7} / \mathrm{C} / \mathrm{CH}(\mathrm{CS})$ & -0.57 & -1.75 & 0.26 & -1.49 & 2.06 & 474 \\
\hline $\mathrm{Ni} / \mathrm{CCH}\left(\mathrm{CC}^{f} \mathrm{~S}\right)$ & 0.33 & -1.13 & 0.19 & -0.94 & 0.61 & \\
\hline $\mathrm{Ni}_{7} / \mathrm{C} \mathrm{CH}_{2}$ (ISS) & -0.39 & -0.42 & 0.30 & -0.12 & 0.51 & \\
\hline $\mathrm{Ni}_{7} / \mathrm{C} / \mathrm{CH}_{2}(\mathrm{CS})$ & -0.56 & -1.59 & 0.82 & -0.77 & 1.33 & 399 \\
\hline $\mathrm{Ni}_{7} / \mathrm{CCH}_{2}\left(\mathrm{CC}^{f} \mathrm{~S}\right)$ & 0.04 & -1.19 & 0.60 & -0.59 & 0.55 & \\
\hline $\mathrm{Ni}_{7} / \mathrm{C}_{\mathrm{CH}}$ (ISS) & -0.39 & -0.30 & 0.33 & 0.03 & 0.36 & \\
\hline $\mathrm{Ni}_{7} / \mathrm{C} \mathrm{CH}_{3}(\mathrm{CS})$ & -0.59 & -1.53 & 1.36 & -0.17 & 0.76 & 303 \\
\hline $\mathrm{Ni}_{7} / \mathrm{CCH}_{3}(\mathrm{TS})$ & -0.60 & -1.37 & 1.30 & -0.07 & 0.67 & \\
\hline $\mathrm{Ni}_{7} / \mathrm{CCH}_{3}\left(\mathrm{CC}^{f} \mathrm{~S}\right)$ & -0.35 & -1.17 & 1.02 & -0.15 & 0.50 & \\
\hline $\mathrm{Ni}_{13} / \mathrm{C} / \mathrm{CH}$ (ISS) & -0.52 & -0.46 & 0.10 & -0.36 & 0.88 & \\
\hline $\mathrm{Ni}_{13} / \mathrm{C} / \mathrm{CH}(\mathrm{CS})$ & -0.65 & -1.65 & 0.31 & -1.34 & 1.99 & 518 \\
\hline $\mathrm{Ni}_{13} / \mathrm{CCH}\left(\mathrm{CC}^{f} \mathrm{~S}\right)$ & 0.55 & -1.20 & 0.13 & -1.07 & 0.52 & \\
\hline $\mathrm{Ni}_{13} / \mathrm{C} \mathrm{CH}_{2}$ (ISS) & -0.52 & -0.53 & 0.28 & -0.25 & 0.77 & \\
\hline $\mathrm{Ni}_{13} / \mathrm{C} / \mathrm{CH}_{2}(\mathrm{CS})$ & -0.65 & -1.72 & 0.92 & -0.80 & 1.45 & 453 \\
\hline $\mathrm{Ni}_{13} / \mathrm{CCH}_{2}\left(\mathrm{CC}^{f} \mathrm{~S}\right)$ & 0.01 & -1.20 & 0.64 & -0.56 & 0.55 & \\
\hline $\mathrm{Ni}_{13} / \mathrm{C} / \mathrm{CH}_{3}$ (ISS) & -0.52 & -0.41 & 0.27 & -0.14 & 0.66 & \\
\hline 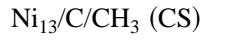 & -0.66 & -1.70 & 1.47 & -0.23 & 0.89 & 335 \\
\hline $\mathrm{Ni}_{13} / \mathrm{CCH}_{3}(\mathrm{TS})$ & -0.58 & -1.49 & 1.42 & -0.07 & 0.65 & \\
\hline $\mathrm{Ni}_{13} / \mathrm{CCH}_{3}\left(\mathrm{CC}^{f} \mathrm{~S}\right)$ & -0.34 & -1.23 & 1.08 & -0.15 & 0.49 & \\
\hline $\mathrm{Co}_{7} / \mathrm{C} / \mathrm{CH}_{3}$ (ISS) & -0.46 & -0.38 & 0.36 & -0.02 & 0.48 & \\
\hline $\mathrm{Co}_{7} / \mathrm{C} \mathrm{CH}_{3}(\mathrm{CS})$ & -0.59 & -1.55 & 1.37 & -0.18 & 0.77 & 280 \\
\hline $\mathrm{Co}_{7} / \mathrm{CCH}_{3}(\mathrm{TS})$ & -0.55 & -1.39 & 1.32 & -0.07 & 0.62 & \\
\hline $\mathrm{Co}_{7} / \mathrm{CCH}_{3}\left(\mathrm{CC}^{f} \mathrm{~S}\right)$ & -0.22 & -1.21 & 1.00 & -0.21 & 0.43 & \\
\hline $\mathrm{Co}_{13} / \mathrm{C} / \mathrm{CH}_{3}$ (ISS) & -0.60 & -0.54 & 0.45 & -0.09 & 0.69 & \\
\hline $\mathrm{Co}_{13} / \mathrm{C}_{\mathrm{CH}}(\mathrm{CS})$ & -0.58 & -1.72 & 1.53 & -0.19 & 0.77 & 300 \\
\hline $\mathrm{Co}_{13} / \mathrm{CCH}_{3}(\mathrm{TS})$ & -0.53 & -1.60 & 1.57 & -0.03 & 0.56 & \\
\hline $\mathrm{Co}_{13} / \mathrm{CCH}_{3}\left(\mathrm{CC}^{f} \mathrm{~S}\right)$ & -0.25 & -1.27 & 1.08 & -0.19 & 0.44 & \\
\hline
\end{tabular}

strongly polarized at the $\mathrm{CS}$ and the $\mathrm{CC}^{f} \mathrm{~S}$ as a result of excessive (negative) charge on $\mathrm{C}$ and positive charge on $\mathrm{H}$ of $\mathrm{CH}$. The total charge on the $\mathrm{CH}$ fragment is as a result also strongly negative at the $\mathrm{CS}$ and to a lesser extend at the $\mathrm{CC}^{f} \mathrm{~S}$. All these observations hold for $\mathrm{C} / \mathrm{CH}_{2}$ too, but they are less pronounced. It is expected that $\mathrm{C} / \mathrm{CH}$ attracts more charge than $\mathrm{C} / \mathrm{CH}_{2}$, resulting in a negatively charged $\mathrm{CH}_{x}$ fragment and a positively charged substrate, but the charge effects seem a bit large. The charge effects at the $\mathrm{CC}^{f} \mathrm{~S}$ of $\mathrm{C} / \mathrm{CH}$ and $\mathrm{C} / \mathrm{CH}_{2}$ could have their cause in the restriction of the $\mathrm{CC}^{f} \mathrm{~S}$ to be perpendicular to the surface, whereas they have probably bent structures. However, the charge effects at the CS and the absence of them at the ISS, together with the large energy difference between ISS and CS suggests the occurrence of finite cluster size effects. For $\mathrm{C} / \mathrm{CH}_{3}$ the charge is always slightly positive on the metal substrate, slightly negative on the $\mathrm{CH}_{3}$ fragment, and slightly more negative on $\mathrm{C}$ in all cases. This is in line with our expectation. The polarization within the $\mathrm{CH}_{3}$ fragment is however again very strong. This effect is present at the CS, the TS, and the $\mathrm{CC}^{f} \mathrm{~S}$ and we feel therefore that the relative energetics at these parts of the potential energy surface can be compared. Again the large charge effects are absent at the ISS. Table II shows that the energy difference between ISS and CS is largest for $\mathrm{C} / \mathrm{CH}$, followed by $\mathrm{C} / \mathrm{CH}_{2}$, and $\mathrm{C} / \mathrm{CH}_{3}$ on $\mathrm{Ni}_{7}$ as well as $\mathrm{Ni}_{13}$. The difference is always largest on the 13-atom clus- ters. Studies on adsorption of $\mathrm{H} / \mathrm{CH}_{3}$ showed an energy difference between the ISS and the CS of $-29 \mathrm{~kJ} / \mathrm{mol}$. Also, no large charge effects were observed. Therefore, in this case the energy difference can be interpreted as a barrier, which has to be overcome to move infinitely separated adsorbed $\mathrm{H}$ and $\mathrm{CH}_{3}$ to adjacent threefold sites. Studies on different coadsorbed positions of $\mathrm{C} / \mathrm{CH}_{3}$ showed an energy difference of $-22 \mathrm{~kJ} / \mathrm{mol}$ between separated threefold sites and adjacent threefold sites. In this case the large charge effects were again observed for both positions, suggesting the comparability of the relative energetics. The energy difference of 22 $\mathrm{kJ} / \mathrm{mol}$ thus indicates a barrier of this size to overcome to move coadsorbed $\mathrm{C} / \mathrm{CH}_{3}$ to adjacent positions. We conclude that when both $\mathrm{C}$ and $\mathrm{CH}_{x}$ are adsorbed (CS, TS, or $\mathrm{CC}^{f} \mathrm{~S}$ ), this gives rise to large charge effects, due to the finite size of our cluster models. This effect is absent at the ISS and in the coadsorption of $\mathrm{H} / \mathrm{CH}_{3}$.

Carter and $\mathrm{Koel}^{18}$ estimated surface reaction energies for many $\mathrm{C}_{x} \mathrm{H}_{x}$ species. For the $\mathrm{CC}$ coupling of $\mathrm{C} / \mathrm{CH}, \mathrm{C} / \mathrm{CH}_{2}$, and $\mathrm{C} / \mathrm{CH}_{3}$ on $\mathrm{Pt}(111)$ forming $\mathrm{CCH}, \mathrm{CCH}_{2}$, and $\mathrm{CCH}_{3}$, they estimated reaction energies of, respectively, $-84,-92$, and $-218 \mathrm{~kJ} / \mathrm{mol}$. Thus according to them all these reactions are thermodynamically favorable on $\mathrm{Pt}(111)$. However, for the $\mathrm{CCH}$, and $\mathrm{CCH}_{2}$ products they assumed bicoordinated structures and for $\mathrm{CCH}_{3}$ a perpendicular structure, while we restricted the $\mathrm{CCH}, \mathrm{CCH}_{2}$, and $\mathrm{CCH}_{3}$ products to perpendicular positions to the surface for reasons of symmetry. Demuth and $\mathrm{Ibach}^{40}$ did not find CC stretch frequencies on $\mathrm{Ni}(111)$ indicative of perpendicular $\mathrm{CCH}$ or $\mathrm{CCH}_{2}$ species. Thus should these species be formed, their CC axis is not perpendicular to the surface.

The work of Shustorovich et al. ${ }^{19}$ is interesting, because they computed chemisorption data of $\mathrm{C}_{x} \mathrm{H}_{x}$ on both $\mathrm{Ni}(111)$ and $\mathrm{Pt}(111)$. Monocoordinated $\mathrm{C}_{2} \mathrm{H}_{x}$ species with a $\mathrm{CC}$-axis perpendicular to the surface and bicoordinated $\mathrm{C}_{2} \mathrm{H}_{x}$ species with a skewed $\mathrm{CC}$ axis have comparable adsorption energies according to the BOC model. For the $\mathrm{CC}$ coupling of $\mathrm{C} / \mathrm{CH}$, $\mathrm{C} / \mathrm{CH}_{2}$, and $\mathrm{C} / \mathrm{CH}_{3}$ on $\mathrm{Pt}(111)$ forming $\mathrm{CCH}, \mathrm{CCH}_{2}$, and $\mathrm{CCH}_{3}$, they estimated reaction energies of, respectively, 0 , -75 , and $+33 \mathrm{~kJ} / \mathrm{mol}$. On $\mathrm{Ni}(111)$ these enthalpies are $+105,+8$, and $+88 \mathrm{~kJ} / \mathrm{mol}$, respectively. For the $\mathrm{CC}$ bond formation of $\mathrm{C} / \mathrm{CH}_{3}$, Shustorovich gives activation barriers of $79 \mathrm{~kJ} / \mathrm{mol}$ on $\mathrm{Pt}(111)$ and $121 \mathrm{~kJ} / \mathrm{mol}$ on $\mathrm{Ni}(111)$, and for the bond cleavage $46 \mathrm{~kJ} / \mathrm{mol}$ on $\mathrm{Pt}(111)$ and $33 \mathrm{~kJ} / \mathrm{mol}$ on $\mathrm{Ni}(111)$. Thus according to Shustorovich, $\mathrm{Pt}(111)$ is the more reactive metal for $\mathrm{CC}$ bond formation, although all chemisorption energies are larger on $\mathrm{Ni}(111)$. In fact, $\mathrm{CC}$ coupling does not take place at all on $\mathrm{Ni}(111)$ according to Shustorovich. Also, his reaction enthalpies on $\mathrm{Pt}(111)$ are less exotherm or even endotherm compared to those of Carter and Koel. For the $\mathrm{C} / \mathrm{CH}_{3}$ reaction on $\mathrm{Pt}(111)$, Carter et al. and Shustorovich give very different results: according to the first it is exothermic by $218 \mathrm{~kJ} / \mathrm{mol}$, while Shustorovich gives an endothermicity of $33 \mathrm{~kJ} / \mathrm{mol}$. We can compare our results with those of Carter and Koel and those of Shustorovich. On first sight, our exothermicity of $215 \mathrm{~kJ} / \mathrm{mol}$ for the $\mathrm{C} / \mathrm{CH}_{3}$ coupling on $\mathrm{Ni}_{7}$ compares very well with the exothermicity of $218 \mathrm{~kJ} / \mathrm{mol}$ for the same reaction on $\mathrm{Pt}(111)$ given by Carter and Koel. If we keep in mind the alleged lesser reac- 
tivity of $\mathrm{Ni}(111)$, it seems better to compare with our 13atom cluster results. In that case our reaction energies of $+61,-14$, and $-66 \mathrm{~kJ} / \mathrm{mol}$ for $\mathrm{C} / \mathrm{CH}, \mathrm{C} / \mathrm{CH}_{2}$, and $\mathrm{C} / \mathrm{CH}_{3}$ coupling show the same trend as those of Carter and Koel of, respectively, $-84,-92$, and $-218 \mathrm{~kJ} / \mathrm{mol}$ on $\mathrm{Pt}(111)$. This is also in agreement with Shustorovich' notion that $\operatorname{Pt}(111)$ is the more reactive metal. Shustorovich' model probably underestimates the exothermicity of the studied surface reactions, as can be concluded from the comparison of his results on $\mathrm{Pt}(111)$ with those of Carter and Koel. We disagree with Shustorovich that the transition state barriers for $\mathrm{CC}$ bond formation are higher than those of $\mathrm{CC}$ bond cleavage.

Kang et al. ${ }^{7}$ have computed the structure of $\mathrm{CCH}_{3}$ on $\mathrm{Pt}(111)$. They found a structure perpendicular to the surface with an adsorbate-substrate distance of $1.20 \AA$, a CC bond distance of $1.70 \AA, \mathrm{CH}$ bond distances of $1.20 \AA$, and $\mathrm{CCH}$ bond angles of $108^{\circ}$. For CCH they also found a preference for a structure perpendicular to the surface, but at a onefold site, with an adsorbate-substrate distance of $1.55 \AA$, a CC bond distance of $1.36 \AA$, and a $\mathrm{CH}$ bond distance of $1.15 \AA$. Koestner et $a l .{ }^{41}$ using a LEED analysis, found on $\mathrm{Rh}(111)$ a perpendicular $\mathrm{CCH}_{3}$ species at a threefold site with a $\mathrm{CC}$ bond distance of $1.45 \AA$, and a MC bond distance of $2.03 \AA$, which corresponds with an adsorbate-substrate distance of $1.31 \AA$. For Pt(111) they give values of $1.50 \AA$ for the $\mathrm{CC}$ bond distance and $2.00 \AA$ for the MC distance, which corresponds with an adsorbate-substrate distance of $1.19 \AA$. It is clear that the computed and experimentally determined CC bond distance on $\mathrm{Pt}(111)$ differ significantly. Our computed $\mathrm{MC}_{1}$ distances of $\mathrm{CCH}_{3}\left(\mathrm{CC}^{f} \mathrm{~S}\right)$ of $1.85 \AA$ on $\mathrm{Ni}_{7}$ and $1.88 \AA$ on $\mathrm{Co}_{7}$, corresponding with adsorbate-substrate distances of 1.16 and $1.21 \AA$, respectively, and our CC bond lengths of $1.57 \AA$ on $\mathrm{Ni}_{7}$ and $1.58 \AA$ on $\mathrm{Co}_{7}$ seem to be reasonable values.

\section{KINETIC CALCULATIONS}

We have computed rate constants using transition state theory. An important advantage of this approach is that the complete potential energy surface is not required. Instead, only the local parts at the coadsorbed state, the transition state, and the CC-formed state need to be determined to compute kinetics. In particular, rotational and vibrational frequencies together with masses of the intermediates and barrier heights determine the rate constant. The formula for CC bond formation is given by

$$
k_{\mathrm{CC}}^{f \mathrm{TST}}=\frac{k_{B} T}{h} \frac{Q_{v}^{\dagger}}{Q_{t} Q_{v}} e^{-E_{\mathrm{crit}} / k_{B} T}
$$

and for $\mathrm{CC}$ bond cleavage by

$$
k_{\mathrm{CC}}^{c \mathrm{TST}}=\frac{k_{B} T}{h} \frac{Q_{v}^{\dagger}}{Q_{v}} e^{-E_{\mathrm{crit}}^{\prime} k_{B} T} .
$$

The translational partition function describes the two translations of $\mathrm{CH}_{3}$, which is a mobile species ${ }^{36}$ on the substrate. The connection between $k_{\mathrm{CC}}^{f}$ TST and $k_{\mathrm{CC}}^{f}$ and between $k_{\mathrm{CC}}^{c}$ TST and $k_{\mathrm{CC}}^{c}$ is discussed in the Appendix. To evaluate
$k_{\mathrm{CC}}^{f}$ TST and $k_{\mathrm{CC}}^{c}$ TST , we need to calculate the translational, vibrational, and rotational partition functions for the CS, the $\mathrm{TS}$ and the $\mathrm{CC}^{f} \mathrm{~S}$.

To find out which degrees of freedom cancel, we characterized them at the different geometries bearing in mind that our cluster represents an (infinite) surface of infinite mass. Therefore, overall translations and rotations of the cluster are irrelevant and internal lattice vibrations (phonons) are neglected. With these premisses we have determined the degrees of freedom at the TS. Three modes determine the absolute position of $\mathrm{C}$ : one $\mathrm{MC}$ stretch $\left(\mathrm{MC}_{1}\right)$, and two vibrations of $\mathrm{C}$ parallel to the surface (one in the mirror plane and one perpendicular to it). Three modes determine the absolute position of $\mathrm{CH}_{3}$ : one $\mathrm{MC}$ stretch $\left(\mathrm{MC}_{2}\right)$, one $\mathrm{CC}$ stretch, and one vibration of $\mathrm{CH}_{3}$ parallel to the surface and perpendicular to the mirror plane. Three modes determine the orientation of $\mathrm{CH}_{3}$ : the $\mathrm{CH}_{3}$ tilt in the mirror plane $(\theta)$, the $\mathrm{CH}_{3}$ tilt perpendicular to the mirror plane, and one internal $\mathrm{CH}_{3}$ rotation around the internal $C_{3 v}$ axis. Finally, there are six internal $\mathrm{CH}_{3}$ modes: three $\mathrm{CH}$ stretches and three internal bending modes adding up to a total of 15 degrees of freedom. For the CS we have again the six internal modes of $\mathrm{CH}_{3}$ and the three modes determining its orientation. Furthermore, we have the $\mathrm{MC}_{2}$ stretch and the two vibrational modes parallel to the surface, which are translations, because $\mathrm{CH}_{3}$ is a very mobile species. Together with the $\mathrm{MC}_{1}$ stretch and the two vibrations of $\mathrm{C}$ parallel to the surface (one in the mirror plane and one perpendicular to it), they add up to 15 degrees of freedom. For the $\mathrm{CC}^{f} \mathrm{~S}$ we have again the six internal $\mathrm{CH}_{3}$ modes and the three modes determining its orientation. Furthermore, we have one $\mathrm{MC}_{1}$ stretch, the two vibrational modes of $\mathrm{C}$ parallel to the surface (one in the mirror plane and one perpendicular to it), one $\mathrm{CC}$ stretch, and the two vibrational modes of $\mathrm{CH}_{3}$ parallel to the surface (one in the mirror plane and one perpendicular to it). Together, these modes add up again to a total of 15 degrees of freedom. The six internal $\mathrm{CH}_{3}$ modes, the internal $\mathrm{CH}_{3}$ rotation and the $\mathrm{CH}_{3}$ tilt perpendicular to the mirror plane cancel at all geometries. Therefore, only the following modes need explicit computation. For the $\mathrm{CS}$ two translations of $\mathrm{CH}_{3}$ on the surface, the $\mathrm{MC}_{1}$ stretch, the $\mathrm{MC}_{2}$ stretch, the two vibrations of $\mathrm{C}$ parallel to the surface (one in the mirror plane and one perpendicular to it), and $\theta$. For the TS the $\mathrm{CC}$ stretch, the $\mathrm{MC}_{1}$ stretch, $\mathrm{MC}_{2}$ stretch, the two vibrations of $\mathrm{C}$ parallel to the surface (one in the mirror plane and one perpendicular to it), one vibration of $\mathrm{CH}_{3}$ parallel to the surface and perpendicular to the mirror plane, and $\theta$. For the $\mathrm{CC}^{f} \mathrm{~S}$ the $\mathrm{MC}_{1}$ stretch, the $\mathrm{CC}$ stretch, the two vibrations of $\mathrm{C}$ parallel to the surface (one in the mirror plane and one perpendicular to it), the two vibrations of $\mathrm{CH}_{3}$ parallel to the surface (one in the mirror plane and one perpendicular to it), and $\theta$. C was kept at a threefold site at all geometries, because it was shown to be very immobile. ${ }^{36}$ Therefore, the $\mathrm{MC}_{1}$ stretch and one vibration of $\mathrm{C}$ parallel to the surface and in the mirror plane are always varied such that their combination keeps $\mathrm{C}$ at the threefold site. Effectively, this reduces our degrees of freedom to be optimized from seven to six. The frequencies are displayed in Table III for the 7- and 13-atom clusters of 
TABLE III. Vibrational frequencies, $\nu_{i}\left(\mathrm{~cm}^{-1}\right)$, of the CS, the TS, and the $\mathrm{CC}^{f} \mathrm{~S}$, of the 7- and 13-atom cluster models.

\begin{tabular}{|c|c|c|c|c|c|c|}
\hline System & $\nu_{1}$ & $\nu_{2}$ & $\nu_{3}$ & $\nu_{4}$ & $\nu_{5}$ & $\nu_{6}$ \\
\hline $\mathrm{Ni}_{7} / \mathrm{C} \mathrm{CH}_{3}(\mathrm{CS})$ & 1663 & 742 & 683 & 387 & & \\
\hline $\mathrm{Ni}_{7} / \mathrm{CCH}_{3}(\mathrm{TS})$ & 573 & 421 & 246 & $167 i$ & 75 & 32 \\
\hline $\mathrm{Ni}_{7} / \mathrm{CCH}_{3}\left(\mathrm{CC}^{f} \mathrm{~S}\right)$ & 2166 & 1082 & 380 & 187 & 177 & 142 \\
\hline $\mathrm{Ni}_{13} / \mathrm{C} / \mathrm{CH}_{3}(\mathrm{CS})$ & 1633 & 551 & 530 & 465 & & \\
\hline $\mathrm{Ni}_{13} / \mathrm{CCH}_{3}(\mathrm{TS})$ & 531 & $421^{\mathrm{a}}$ & 336 & $233 i$ & $75^{\mathrm{a}}$ & 28 \\
\hline $\mathrm{Ni}_{13} / \mathrm{CCH}_{3}\left(\mathrm{CC}^{f} \mathrm{~S}\right)$ & 2040 & 950 & 354 & $187^{\mathrm{a}}$ & $177^{\mathrm{a}}$ & 121 \\
\hline $\mathrm{Co}_{7} / \mathrm{C} / \mathrm{CH}_{3}(\mathrm{CS})$ & 1001 & 895 & 438 & 365 & & \\
\hline $\mathrm{Co}_{7} / \mathrm{CCH}_{3}(\mathrm{TS})$ & 537 & 427 & 286 & 118 & $100 i$ & 46 \\
\hline $\mathrm{Co}_{7} / \mathrm{CCH}_{3}\left(\mathrm{CC}^{f} \mathrm{~S}\right)$ & 2274 & 1058 & 395 & 161 & 153 & 110 \\
\hline $\mathrm{Co}_{13} / \mathrm{C} / \mathrm{CH}_{3}(\mathrm{CS})$ & 1068 & 634 & 556 & 529 & & \\
\hline $\mathrm{Co}_{13} / \mathrm{CCH}_{3}(\mathrm{TS})$ & 553 & $427^{\mathrm{b}}$ & 348 & $240 i$ & $118^{\mathrm{b}}$ & 28 \\
\hline $\mathrm{Co}_{13} / \mathrm{CCH}_{3}\left(\mathrm{CC}^{f} \mathrm{~S}\right)$ & 2114 & 910 & 340 & $161^{\mathrm{b}}$ & $153^{\mathrm{b}}$ & 121 \\
\hline
\end{tabular}

${ }^{\mathrm{a}}$ Modes of the $\mathrm{Ni}_{7}$ cluster.

${ }^{b}$ Modes of the $\mathrm{Co}_{7}$ cluster.

nickel and cobalt. The imaginary frequency at the TS is dominated by the $\mathrm{CC}$ stretch in all cases.

As discussed in Sec. I, $\mathrm{CCH}_{3}$ has been identified experimentally by various methods. Goodman et al., ${ }^{5}$ Steiniger et al., ${ }^{11}$ Parmeter et al., ${ }^{42}$ Kesmodel et al., ${ }^{43}$ Koel et al., ${ }^{44}$ and Skinner et al. ${ }^{45}$ give vibrational frequencies of $\mathrm{CCH}_{3}$ $\left(\mathrm{CC}^{f} \mathrm{~S}\right)$ on $\mathrm{Ru}(1120), \mathrm{Ru}(0001), \operatorname{Pt}(111), \operatorname{Pd}(111), \mathrm{Rh}(111)$, and the organometallic cluster $\mathrm{Co}_{3}\left(\mathrm{CCH}_{3}\right) \mathrm{CO}_{9}$. These groups measured the symmetrical and asymmetrical $\mathrm{CH}$ stretch, the symmetrical and asymmetrical scissors mode, and the rocking vibration of the $\mathrm{CH}_{3}$ group, in addition to the $\mathrm{CC}$ stretch and the MC stretch. Our choice of modes results in the cancellation of various partition functions, which allows computation of rate constants. However, it makes comparison with this data less straightforward. Therefore, we will restrict the comparison to the $\mathrm{CC}$ stretch and the $\mathrm{MC}$ stretch. For the $\mathrm{CC}$ stretch frequency we found values of 1082, 1058, 950, and $910 \mathrm{~cm}^{-1}$ on $\mathrm{Ni}_{7}, \mathrm{Co}_{7}, \mathrm{Ni}_{13}$, and $\mathrm{Co}_{13}$, respectively. Experimentally they range between $1080-1163 \mathrm{~cm}^{-1} \cdot 15,11,33-36$ For the MC stretch frequency we found values of 380, 395, 354, and $340 \mathrm{~cm}^{-1}$ on $\mathrm{Ni}_{7}, \mathrm{Co}_{7}, \mathrm{Ni}_{13}$, and $\mathrm{Co}_{13}$, respectively. Experimentally they range between $220-600 \mathrm{~cm}^{-1}$. $15,11,33-36$ Although no data on $\mathrm{Ni}$ or Co surfaces could be found, it is clear from these data that our computed frequencies seem correct and are well suited for the computation of rate constants via vibrational partition functions.

These rate constants for $\mathrm{CC}$ bond formation and cleavage are calculated according to Eqs. (3) and (4), and are shown in Table IV at different temperatures. It is clear from Table IV that for all temperatures and for all clusters CC bond formation prevails over $\mathrm{CC}$ bond cleavage. We see that the rate constant for $\mathrm{CC}$ bond formation is a factor 6-13 larger on $\mathrm{Ni}_{7}$ compared to $\mathrm{Co}_{7}$ in the temperature range studied, although the barrier height on $\mathrm{Ni}_{7}$ is slightly higher at the electronic potential energy surface. This is due to the effect of vibrational zero-point energies and temperature on the barrier height. This is more clearly seen from Table V, which gives the barrier heights at the electronic potential energy surface $(E)$, including zero-point energy differences $\left(E_{\text {crit }}\right)$, and including temperature effects $\left(E_{\text {act }}\right) . E_{\text {act }}$ is given by the slope of Arrhenius plots, which are shown in Figs.
TABLE IV. Rate constants for CC bond formation $\left(k_{\mathrm{CC}}^{f}\right)\left(\mathrm{m}^{2} \mathrm{~s}^{-1}\right)$ and $\mathrm{CC}$ bond cleavage $\left(k_{\mathrm{CC}}^{c}\right)\left(\mathrm{s}^{-1}\right)$ for the 7 - and 13-atom cluster models for different temperatures.

\begin{tabular}{lrcc}
\hline \hline System & \multicolumn{1}{c}{$T$} & $k_{\mathrm{CC}}^{f}$ & $k_{\mathrm{CC}}^{c}$ \\
\hline $\mathrm{Ni}_{7} / \mathrm{CCH}_{3}$ & 250 & $5.99 \cdot 10^{-17}$ & $1.64 \cdot 10^{-40}$ \\
$\mathrm{Ni}_{7} / \mathrm{CCH}_{3}$ & 500 & $1.10 \cdot 10^{-11}$ & $1.81 \cdot 10^{-13}$ \\
$\mathrm{Ni}_{7} / \mathrm{CCH}_{3}$ & 750 & $9.10 \cdot 10^{-10}$ & $2.33 \cdot 10^{-04}$ \\
$\mathrm{Ni}_{7} / \mathrm{CCH}_{3}$ & 1000 & $9.62 \cdot 10^{-09}$ & $9.07 \cdot 10^{+00}$ \\
$\mathrm{Ni}_{13} / \mathrm{CCH}_{3}$ & 250 & $4.91 \cdot 10^{-23}$ & $1.36 \cdot 10^{-15}$ \\
$\mathrm{Ni}_{13} / \mathrm{CCH}_{3}$ & 500 & $8.62 \cdot 10^{-15}$ & $4.37 \cdot 10^{-01}$ \\
$\mathrm{Ni}_{13} / \mathrm{CCH}_{3}$ & 750 & $6.80 \cdot 10^{-12}$ & $3.64 \cdot 10^{+04}$ \\
$\mathrm{Ni}_{13} / \mathrm{CCH}_{3}$ & 1000 & $2.19 \cdot 10^{-10}$ & $1.13 \cdot 10^{+07}$ \\
$\mathrm{Co}_{7} / \mathrm{CCH}_{3}$ & 250 & $4.51 \cdot 10^{-18}$ & $2.21 \cdot 10^{-34}$ \\
$\mathrm{Co}_{7} / \mathrm{CCH}_{3}$ & 500 & $1.60 \cdot 10^{-12}$ & $1.04 \cdot 10^{-10}$ \\
$\mathrm{Co}_{7} / \mathrm{CCH}_{3}$ & 750 & $1.56 \cdot 10^{-10}$ & $1.01 \cdot 10^{-02}$ \\
$\mathrm{Co}_{7} / \mathrm{CCH}_{3}$ & 1000 & $1.73 \cdot 10^{-09}$ & $1.08 \cdot 10^{+02}$ \\
$\mathrm{Co}_{13} / \mathrm{CCH}_{3}$ & 250 & $3.62 \cdot 10^{-16}$ & $4.55 \cdot 10^{-13}$ \\
$\mathrm{Co}_{13} / \mathrm{CCH}_{3}$ & 500 & $1.93 \cdot 10^{-11}$ & $5.23 \cdot 10^{+00}$ \\
$\mathrm{Co}_{13} / \mathrm{CCH}_{3}$ & 750 & $9.94 \cdot 10^{-10}$ & $1.42 \cdot 10^{+05}$ \\
$\mathrm{Co}_{13} / \mathrm{CCH}_{3}$ & 1000 & $8.05 \cdot 10^{-09}$ & $2.51 \cdot 10^{+07}$ \\
\hline \hline
\end{tabular}

2(a) -2(b) for both $\mathrm{Ni}_{7} / \mathrm{Co}_{7}$ and $\mathrm{Ni}_{13} / \mathrm{Co}_{13}$. The intercepts of the Arrhenius plots give the pre-exponentials $\left(A_{\text {plot }}\right)$, which are also given in Table $\mathrm{V}$. We see that inclusion of zero-point energies lowers barrier heights for both $\mathrm{CC}$ bond formation as well as CC bond cleavage, reflecting the relatively low vibrational frequencies at the TS and the relatively high frequencies at the CS and the $\mathrm{CC}^{f} \mathrm{~S}$. The effect of temperature is the population of excited levels, which affects the TS more strongly than the CS and the $\mathrm{CC}^{f} \mathrm{~S}$, because of its lower frequencies. The temperature averaged barrier $\left(E_{\text {act }}\right)$ will therefore be higher than the critical barrier $E_{\text {crit }}$, where only the zero-point energy differences are taken into account. For $\mathrm{CC}$ bond formation on $\mathrm{Ni}_{13}$ and $\mathrm{Co}_{13}$ the barrier height at the electronic potential energy surface $(E)$, including zero-point energy differences $\left(E_{\text {crit }}\right)$, and temperature averaged $\left(E_{\text {act }}\right)$, is substantially lower on $\mathrm{Co}_{13}$. Therefore, the rate constants on these clusters are far more larger on $\mathrm{Co}_{13}$ than on $\mathrm{Ni}_{13}$ at all temperatures. If there is no entropy of activation, the preexponential factor is approximately $10^{-6} \mathrm{~m}^{2} \mathrm{~s}^{-1}$ for CC bond formation, which is a bimolecular surface reaction, and approximately $10^{+13} \mathrm{~s}^{-1}$ for $\mathrm{CC}$ bond cleavage, which is a unimolecular surface reaction. ${ }^{30}$ The pre-exponentials for $\mathrm{CC}$ bond formation denote therefore that there is essentially no entropy of activation and that thus the entropy in the CS and

TABLE V. Electronic energy $(E)(\mathrm{kJ} / \mathrm{mol})$, critical energy $\left(E_{\text {crit }}\right)(\mathrm{kJ} / \mathrm{mol})$, activation energy $\left(E_{\text {act }}\right)(\mathrm{kJ} / \mathrm{mol})$, and Arrhenius pre-exponential $\left(A^{\text {plot }}\right)$ for $\mathrm{CC}$ bond formation $\left(\mathrm{m}^{2} \mathrm{~s}^{-1}\right)$ and $\mathrm{CC}$ bond cleavage $\left(\mathrm{s}^{-1}\right)$ for the 7- and 13-atom cluster models.

\begin{tabular}{lcrrrc}
\hline \hline System & Reaction & $E$ & $E_{\text {crit }}$ & $E_{\text {act }}$ & $A^{\text {plot }}$ \\
\hline $\mathrm{Ni}_{7} / \mathrm{CCH}_{3}$ & CC bond formation & 57 & 44 & 52 & $3.98 \cdot 10^{-06}$ \\
$\mathrm{Ni}_{7} / \mathrm{CCH}_{3}$ & CC bond cleavage & 271 & 255 & 260 & $2.96 \cdot 10^{+14}$ \\
$\mathrm{Ni}_{13} / \mathrm{CCH}_{3}$ & CC bond formation & 84 & 73 & 80 & $2.81 \cdot 10^{-06}$ \\
$\mathrm{Ni}_{13} / \mathrm{CCH}_{3}$ & CC bond cleavage & 150 & 135 & 140 & $1.99 \cdot 10^{+14}$ \\
$\mathrm{Co}_{7} / \mathrm{CCH}_{3}$ & CC bond formation & 55 & 48 & 55 & $1.00 \cdot 10^{-06}$ \\
$\mathrm{Co}_{7} / \mathrm{CCH}_{3}$ & $\mathrm{CC}$ bond cleavage & 240 & 223 & 228 & $7.25 \cdot 10^{+13}$ \\
$\mathrm{Co}_{13} / \mathrm{CCH}_{3}$ & $\mathrm{CC}$ bond formation & 47 & 40 & 47 & $1.81 \cdot 10^{-06}$ \\
$\mathrm{Co}_{13} / \mathrm{CCH}_{3}$ & $\mathrm{CC}$ bond cleavage & 136 & 122 & 126 & $8.37 \cdot 10^{+13}$ \\
\hline \hline
\end{tabular}




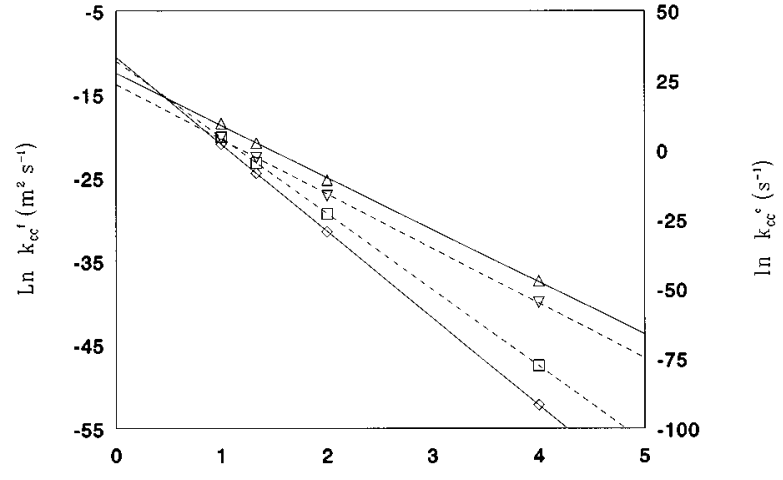

(a)

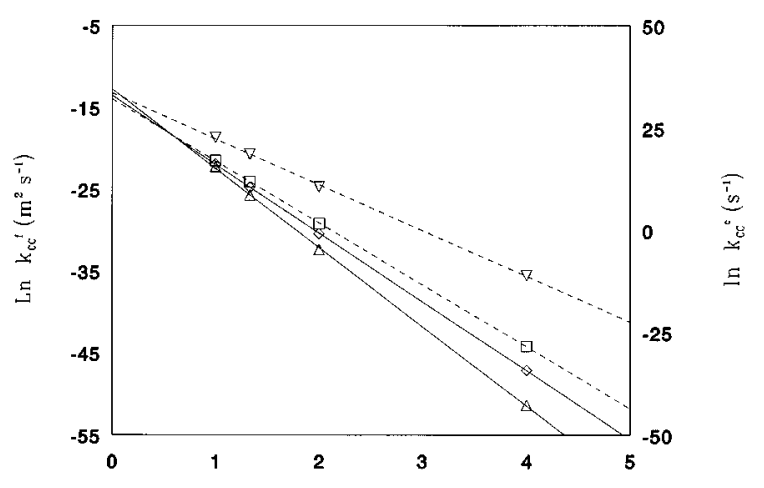

(b)

$1000 \mathrm{~K} / \mathrm{T}$ and the barrier height correlates with the change of the $\mathrm{CC}$ bond in going from the CS to the TS and from the $\mathrm{CC}^{f} \mathrm{~S}$ to the TS. The magnitude of this effect is different for the 7-clusters and the 13-clusters.

Finite cluster size effects were observed for all CC coupling reactions by comparing the charge distributions on $\mathrm{C}$, $\mathrm{CH}_{x}$, and on the substrate at all studied parts of the potential energy surface, in combination with the energy difference between the adsorbed $\mathrm{C} / \mathrm{CH}_{x}$ in the ISS and the CS. For the $\mathrm{CC}^{f} \mathrm{~S}$ of $\mathrm{C} / \mathrm{CH}$ and $\mathrm{C} / \mathrm{CH}_{2}$ a possible cause of the positive charge on $\mathrm{C}$ is the restriction of geometries perpendicular to the surface. For $\mathrm{C} / \mathrm{CH}_{3}$ the charge is always slightly positive on the substrate, slightly negative on $\mathrm{CH}_{3}$, and slightly more negative on $\mathrm{C}$, which is in line with our expectation. However, the polarization within the $\mathrm{CH}_{3}$ fragment is again very strong. This effect is present at the CS, the TS, and the $\mathrm{CC}^{f} \mathrm{~S}$ and we feel therefore that the relative energies at these parts of the potential energy surface are comparable. Coadsorption of $\mathrm{H} / \mathrm{CH}_{3}$ showed no finite cluster effects.

We have seen that the rate constant for $\mathrm{CC}$ bond formation is a factor 6-13 larger on $\mathrm{Ni}_{7}$ compared to $\mathrm{Co}_{7}$, although the barrier height on $\mathrm{Ni}_{7}$ is slightly higher at the electronic potential energy surface. This is due to the effect of vibrational zero-point energies and temperature on the barrier height. For $\mathrm{CC}$ bond formation on $\mathrm{Ni}_{13}$ and $\mathrm{Co}_{13}$ the barrier height is always substantially lower on $\mathrm{Co}_{13}$, whether zero-point energies and temperature effects are included or not. Therefore, the rate constants on these clusters are always far more larger on $\mathrm{Co}_{13}$ than on $\mathrm{Ni}_{13}$. The TS was shown to be rather tight.

\section{ACKNOWLEDGMENTS}

All calculations were performed with the ADF program on the Cray Y-MP4/464 at SARA, Amsterdam. This work has been supported by the Netherlands Foundation for Chemical Research (SON) with financial aid from the Netherlands Organization of Pure and Scientific Research (NWO). The computer time on the Cray Y-MP4/464 was subsidized by the Foundation for the use of supercomputers, National Computing Facilities (NCF).

\section{APPENDIX: DERIVATION OF RATE CONSTANT EQUATIONS}

We can write down the following for CC bond formation:

$$
\frac{d}{d t} N_{\mathrm{CCH}_{3 a}}=k_{\mathrm{CC}}^{f}{ }^{\mathrm{TST}} N_{\mathrm{C}_{a}} N_{\mathrm{CH}_{3 a}},
$$

where, $N_{\mathrm{CCH}_{3 a}}$ is the number of adsorbed $\mathrm{CCH}_{3}$ molecules, $N_{\mathrm{C}_{a}}$ is the number of adsorbed $\mathrm{C}$ molecules, and $N_{\mathrm{CH}_{3 a}}$ is the number of adsorbed $\mathrm{CH}_{3}$ molecules. $k_{\mathrm{CC}}^{f}$ TST is the transition state theory reaction rate constant given by

$$
k_{\mathrm{CC}}^{f \mathrm{TST}}=\frac{k_{B} T}{h} \frac{Q_{v_{1}}^{\dagger} \cdots Q_{v_{5}}^{\dagger}}{Q_{t_{1}} Q_{t_{2}} Q_{v_{1}} \cdots Q_{v_{4}}} e^{-E_{\text {crit }} / k_{B} T} .
$$

The translational partition functions $Q_{t_{1}}$, and $Q_{t_{2}}$ can be combined and are of the form 


$$
\left(2 \pi m_{\mathrm{CH}_{3}} k_{B} T / h^{2}\right) S .
$$

All vibrational partition functions $Q_{v}$ are of the form

$$
\frac{1}{1-e^{-(h \nu) /\left(k_{B} T\right)}} \text {. }
$$

In Eqs. (A2)-(A4), $k_{B}$ denotes Boltzmann's constant, $T$ temperature, $h$ Planck's constant, $E_{\text {crit }}$ the barrier energy including zero-point energy differences, $\nu$ the frequency of the particular vibrational mode, $S$ the surface area, and $m_{\mathrm{CH}_{3}}$ the mass of $\mathrm{CH}_{3}$. The translational modes of $\mathrm{CH}_{3}$ enter because $\mathrm{CH}_{3}$ is a mobile species. As a consequence of our tight TS, the activated $\mathrm{CCH}_{3}$ is immobile and bound to one specific site. Changing to surface concentrations Eq. (A1) can be written as

$$
\frac{1}{S} \frac{d}{d t} N_{\mathrm{CCH}_{3 a}}=k_{\mathrm{CC}}^{f} \operatorname{TST}_{S} \frac{N_{\mathrm{C}_{a}}}{S} \frac{N_{\mathrm{CH}_{3 a}}}{S}
$$

or equivalently,

$$
\frac{d}{d t}\left[\mathrm{CCH}_{3}\right]_{a}=k_{\mathrm{CC}}^{f \mathrm{TST}} S[\mathrm{C}]_{a}\left[\mathrm{CH}_{3}\right]_{a},
$$

or

$$
\frac{d}{d t}\left[\mathrm{CCH}_{3}\right]_{a}=k_{\mathrm{CC}}^{f}[\mathrm{C}]_{a}\left[\mathrm{CH}_{3}\right]_{a} .
$$

We therefore have $k_{\mathrm{CC}}^{f}=k_{\mathrm{CC}}^{f}{ }^{\mathrm{TST}} S$. Note that the surface area $S$ in Eqs. (A3) and (A6) cancel.

For the $\mathrm{CC}$ bond cleavage we can write down the following:

$$
\frac{d}{d t} N_{\mathrm{CCH}_{3 a}}=-k_{\mathrm{CC}}^{c}{ }^{\mathrm{TST}} N_{\mathrm{CCH}_{3 a}} .
$$

Here, $N_{\mathrm{CCH}_{3 a}}$ is again the number of adsorbed $\mathrm{CCH}_{3}$ molecules, and $k_{\mathrm{CC}}^{c}$ TST is the transition state theory rate constant for $\mathrm{CC}$ bond cleavage given by

$$
k_{\mathrm{CC}}^{c} \mathrm{TST}=\frac{k_{B} T}{h} \frac{Q_{v_{1}}^{\dagger} \cdots Q_{v_{5}}^{\dagger}}{Q_{v_{1}} \cdots Q_{v_{6}}} e^{-E_{\text {cril }}^{\prime} k_{B} T} .
$$

Changing to surface concentrations Eq. (A8) can be written as

$$
\frac{1}{S} \frac{d}{d t} N_{\mathrm{CCH}_{3 a}}=-k_{\mathrm{CC}}^{c} \mathrm{TST} \frac{1}{S} N_{\mathrm{CCH}_{3 a}},
$$

or equivalently,

$$
\left.\frac{d}{d t}\left[\mathrm{CCH}_{3}\right]_{a}=-k_{\mathrm{CC}}^{c} \mathrm{TST}^{\mathrm{CCCH}}\right]_{a}
$$

or

$$
\frac{d}{d t}\left[\mathrm{CCH}_{3}\right]_{a}=-k_{\mathrm{CC}}^{c}\left[\mathrm{CCH}_{3}\right]_{a} .
$$

Therefore, $k_{\mathrm{CC}}^{c}$ and $k_{\mathrm{CC}}^{c} \mathrm{TST}$ are equivalent.

${ }^{1}$ F. Fischer and H. Tropsch, Brennst. Chem. 7, 97 (1926); Chem. Ber. 59, 830 (1926)
${ }^{2}$ R. C. Brady III and R. Pettit, J. Am. Chem. Soc. 102, 6181 (1980); 103, 1287 (1981)

${ }^{3}$ M. P. Kaminsky, N. Winograd, G. L. Geoffroy, and M. A. Vannice, J. Am. Chem. Soc. 108, 1315 (1986).

${ }^{4}$ T. Koerts and R. A. van Santen, J. Chem. Soc. Chem. Commun. 1281 (1991); T. Koerts, M. J. A. G. Deelen, and R. A. van Santen, J. Catal. 138, 101 (1992).

${ }^{5}$ M. C. Wu and D. W. Goodman, J. Am. Chem. Soc. 116, 1364 (1994); M. C. Wu, D. W. Goodman, and G. W. Zajac, Catal. Lett. 24, 23 (1994); M. C. Wu, P. Lenz-Solomun, and D. W. Goodman, J. Vac. Sci. Tech. A 12, 2205 (1994).

${ }^{6}$ M. Belgued, P. Pareja, A. Amariglio, and H. Amariglio, Nature (London) 352, 789 (1991).

${ }^{7}$ D. B. Kang and A. B. Anderson, Surf. Sci. 155, 639 (1985).

${ }^{8}$ G. A. Somorjai, M. A. Van Hove, and B. E. Bent, J. Phys. Chem. 92, 973 (1988).

${ }^{9}$ R. G. Windham and B. E. Koel, J. Phys. Chem. 94, 1489 (1990).

${ }^{10}$ F. Zaera, J. Am. Chem. Soc. 111, 4240 (1989).

${ }^{11}$ H. Steiniger, H. Ibach, and S. Lehwald, Surf. Sci. 117, 341 (1982); M. Salmeron and G. A. Somorjai, J. Phys. Chem. 86, 341 (1982); J. R. Creighton and J. M. White, Surf. Sci. 129, 327 (1983); M. R. Albert, L. G. Sneddon, W. Eberhardt, F. Greuter, T. Gustafson, and E. W. Plummer, ibid. 120, 19 (1982).

${ }^{12}$ D. H. Fairbrother, X. D. Peng, R. Viswanathan, P. C. Stair, M. Trenary, and J. Fan, Surf. Sci. Lett. 285, L455 (1993).

${ }^{13}$ F. Zaera and H. Hoffmann, J. Phys. Chem. 95, 6297 (1991).

${ }^{14}$ C. Zheng, Y. Apeloig, and R. Hoffmann, J. Am. Chem. Soc. 110, 749 (1988).

${ }^{15}$ A. de Koster and R. A. van Santen, J. Catal. 127, 141 (1991).

${ }^{16}$ T. Koerts and R. A. van Santen, J. Mol. Catal. 70, 119 (1991).

${ }^{17}$ L. L. Kesmodel, L. H. Dubois, and G. A. Somorjai, Chem. Phys. Lett. 56, 267 (1978); J. Chem. Phys. 70, 2180 (1979).

${ }^{18}$ E. A. Carter and B. E. Koel, Surf. Sci. 226, 339 (1990).

${ }^{19}$ E. Shustorovich, Surf. Sci. 205, 336 (1988); Adv. Catal. 37, 101 (1990).

${ }^{20}$ S. Lehwald and H. Ibach, Surf. Sci. 89, 425 (1979).

${ }^{21}$ J. E. Demuth, Surf. Sci. 76, L603 (1978).

${ }^{22}$ J. A. Stroscio, S. R. Bare, and W. Ho, Surf. Sci. 148, 499 (1984).

${ }^{23}$ F. Zaera and R. B. Hall, Surf. Sci. 180, 1 (1987).

${ }^{24}$ X. Y. Zhu and J. M. White, Surf. Sci. 214, 240 (1989).

${ }^{25}$ M. R. Albert, L. G. Sneddon, and E. W. Plummer, Surf. Sci. 147, 127 (1984).

${ }^{26}$ M. P. Lapinski and J. G. Ekerdt, J. Phys. Chem. 92, 1708 (1988).

${ }^{27}$ K. G. Anderson and J. G. Ekerdt, J. Catal. 116, 556 (1989).

${ }^{28}$ H. Burghgraef, A. P. J. Jansen, and R. A. van Santen, J. Chem. Phys. 101, 11012 (1994).

${ }^{29}$ Amsterdam density-functional (ADF) program developed by Baerends and co-workers. E. J. Baerends, D. E. Ellis, and P. Ros, Chem. Phys. 2, 41 (1973); P. M. Boerrigter, G. te Velde, and E. J. Baerends, Int. J. Quantum Chem. 33, 87 (1988); G. te Velde and E. J. Baerends, J. Comput. Phys. 99, 84 (1992); D. Post and E. J. Baerends, J. Chem. Phys. 78, 5663 (1983); E. J. Baerends and A. Rozendaal, Quantum Chemistry: The Challenge of Transition Metals and Coordination Chemistry, edited by A. Veillard (Reidel, Dordrecht, 1986); P. J. van den Hoek, A. W. Kleyn, and E. J. Baerends, Commun. At. Mol. Phys. 23, 93 (1989).

${ }^{30}$ D. M. Ceperley and B. J. Alder, Phys. Rev. Lett. 45, 566 (1980).

${ }^{31}$ S. H. Vosko, L. Wilk, and M. Nusair, Can. J. Phys. 58, 1200 (1980); J. P. Perdew and A. Zunger, Phys. Rev. B 23, 5048 (1981).

${ }^{32}$ A. D. Becke, Int. J. Quantum Chem. 27, 585 (1985).

${ }^{33}$ A. D. Becke, Phys. Rev. A 38, 3098 (1988).

${ }^{34}$ H. Stoll, C. M. E. Pavlidou, and H. Preuss, Theor. Chim. Acta 49, 143 (1978); H. Stoll, E. Golka, and H. Preuss, ibid. 55, 29 (1980).

${ }^{35}$ J. G. Snijders and E. J. Baerends, Mol. Phys. 36, 1789 (1978); J. G. Snijders, E. J. Baerends, and P. Ros, ibid. 38, 1909 (1979).

${ }^{36}$ H. Burghgraef, A. P. J. Jansen, and R. A. van Santen, Surf. Sci. 324, 345 (1995).

${ }^{37}$ T. Ziegler and A. Rauk, Theor. Chim. Acta 46, 1 (1977).

${ }^{38}$ E. B. Wilson, J. C. Decius, and P. C. Cross, Molecular Vibrations. Theory of Infrared and Raman Vibrational Spectra (McGraw-Hill, New York, 1955).

${ }^{39}$ R. G. Gilbert and S. C. Smith, Theory of Unimolecular and Recombination Reactions (Blackwell, Oxford, 1990); M. Boudart and G. DjégaMariadassou, Kinetics of Heterogeneous Catalytic Reactions (Princeton 
University, Princeton, 1984); V. P. Zhdanov, J. Pavlicek, and Z. Knorr, Catal. Rev. Sci. Eng. 30, 501 (1988).

${ }^{40}$ J. E. Demuth and H. Ibach, Surf. Sci. 78, L238 (1978).

${ }^{41}$ R. J. Koestner, M. A. van Hove, and G. A. Somorjai, Surf. Sci. 121, 321 (1982).
${ }^{42}$ J. E. Parmeter, M. M. Hills, and W. H. Weinberg, J. Am. Chem. Soc. 108, 3563 (1986).

${ }^{43}$ L. L. Kesmodel and J. A. Gates, Surf. Sci. 111, L747 (1981).

${ }^{44}$ B. E. Koel, B. E. Bent, and G. A. Somorjai, Surf. Sci. 146, 211 (1984).

${ }^{45}$ P. Skinner, M. W. Howard, I. A. Oxton, S. F. A. Kettle, D. B. Powell, and N. Sheppard, J. Chem. Soc. Far. Trans. 77, 1203 (1981). 